\title{
Caosgrafias cidade*
}

\section{Chaosgraphies city}

Frederico de Araujo

\section{Resumo}

Caosgrafias nomeia um modo de construção coletiva de discursos que navega entre ciência, arte e filosofia. Aciona a prática cartográfica enquanto trama de afectos, associada à noção de caos como possibilidade do devir. Pode ser dita, então, como modo "caótico" de composição de grafias enquanto potência a criação de discursos; como uma aventura corpóreo-palavreira, que busca instaurar tensionamentos no processo de instituição e narrativa do objeto experienciado. As caosgrafias são, assim, inventadas como "acontecimentos desconstrução", não no sentido de "terra arrasada", mas sinalizando o intuito de que o experienciar problematize o dizer logocêntrico, em termos tanto de derrubamento de absolutos, quanto de transgressão poiética. Este trabalho - Caosgrafias cidade - exercita esse modo caosgráfico de construção de discursos com o tema "cidade".

Palavras-chave: experiência; narrativa; cidade; discurso; escritura.

\begin{abstract}
Chaosgraphies refers to a means of collective construction of discourses that navigates among science, art and philosophy. It uses cartographic practice as affective plotting, associated with the notion of chaos as a possibility of "becoming". It can be understood as a "chaotic" means of graphical composition towards the creation of discourses, or as a corporeal/word-based adventure that seeks to establish tensions in the process of instituting and narrating experiences of objects. Chaosgraphies, therefore, are "deconstructed happenings: " rather than being "scorched earth" practices, they signal an intention in which experience problematizes logocentric speech by overturning absolutes and also through poietic transgression. Chaosgraphies city exercises this chaosgraphical means of constructing discourses whose theme is "the city."
\end{abstract}

Keywords: experience; narrative; city; discourse; written word. 
A cidade com seus olhos enormes, onde tudo pode acontecer, aberta ao aleatório, carrega, no vão aberto entre a noite e o dia, a fuga imaginada para as estrelas. Ninguém conhece seu começo ou fim, nem as placas que anunciam a chegada nem o rio que corta sua silhueta. Dizem que o caminho para Pasárgada passa por entre seus becos e vielas e arcos e chuvas finas e tascas e avenidas. ${ }^{1}$

\section{e introdução e aproximações e (des)norteamentos e}

Como pôr em palavras/escrever sobre algo que foi pensado enquanto estratégia, dispositivo de experimentação corpóreo-discursivo-performático ou prática de um dizer? Algo que não quer ser visto como uma coisa objetiva no mundo para ser explicada nem como uma possibilidade metodológica de separação subjetiva desse mundo, capaz de explicar ou cartografar algo aí? Como dizê-lo, portanto? Melhor não seria, então, simplesmente contar sem receio de prosear por demais (ou até gaguejar) sobre o que ali se viu, se produziu, aconteceu?

Pois é o que viemos fazendo com as caosgrafias: dar notícias de algo que resta do que temos experimentado, de modo coletivo, a partir de um exercício de desconstrução de dizeres existentes que se querem absolutos, necessários. 0 que é sempre um exercício de afirmação de dizeres outros e de dizeres múltiplos - expondo-os, dispondo-os. Incitando-os a um jogo, a uma arena.

Talvez não possamos dizer com toda precisão ou certeza do por que, hoje, do desejo de tomar a escrita como forma de dar lugar a essas experienciações (não são todos entre nós que se convenceram disso). Será, no entanto, a própria escritura deste texto, o próprio ato de fazer do texto não uma re-apresentação, mas uma tradução como reinvenção, capaz de fazer saltar esse(s) motivo(s)? Será a leitura das palavras que por fim ficam grafadas na superfície do papel ou da tela o movimento que pode nos reenviar à pertinência de fazer da caosgrafia texto? Movimento que encontrará alguma razão para essa tentativa? Não esperamos concordância nem pretendemos convencer, muito menos responder. Nisso concordamos. E, ao menos - assim também estamos de acordo -, esperamos que a textura que aqui ganha caosgrafia nos acosse, inquiete questões, desassossegos -, isto já nos dará motivos. Ainda que de pequenas alegrias. Segue, pois, a tentativa.

0 que denominamos caosgrafias resulta da posição ético-estética por navegar no limiar entre ciência, arte e filosofia, articulando teorias e práticas com a experiência estética envolvida nos atos de dizer (e criar) cidade através de múltiplas linguagens em meio a atividades que proferem temas e problemas da cidade contemporânea. Associamos essa prática à noção de $\operatorname{caos}^{2}{ }^{2}$ acionado não como sinônimo de desordem, mas como o meio de 
todas as possibilidades do devir, habitado por fluxos de intensidades e afectos. Concebemos, assim, "caosgrafias cidade" como modo "caótico" de constituição de grafias como potência máxima às possibilidades de criação de narrativas cidade.

Optamos, neste ensaio, pela forma de fragmentos caosgráficos (aforismos), a fim de evidenciar posição que visa a romper com linearidades, causalidades e hierarquia tão recorrentes nos discursos que queremos desconstruir, mas também porque assumir uma estética do fragmento e uma ética do paradoxo, parece-nos a melhor condição a um processo de feitura realizado por muitas pessoas que não precisam e/ou não desejam concordar ou chegar a uma síntese totalizadora, ou conclusão, ou verdade. Dessa forma, autorizamo-nos a dizer das caosgrafias como prática política coletiva que, quando produz reverberações potentes, pode contribuir enquanto provocação, tensionamento e/ou desestabilização no debate do fazer, instituir e pensar cidade.

Com caosgrafias nos aproximamos do aporte teórico desenvolvido por Suely Rolnik, que propõe uma cartografia cuja realização demanda a ativação de um corpo vibrátil,

capaz de apreender a alteridade em sua condição de campo de forças vivas que nos afetam e se fazem presentes em nosso corpo [...]. 0 exercício dessa capacidade está desvinculado da história do sujeito e da linguagem. Com ela, o outro é uma presença que se integra à nossa textura sensivel, tornando-se assim parte de nós mesmos. Dissolvem-se aqui as figuras de sujeito e objeto, e com elas aquilo que separa o corpo do mundo. (Rolnik, 2006, p. 12)
Cartografar aí consiste em decodificar, desarranjar e embaralhar as variações de códigos enraizadas em nossos territórios existenciais para poder experimentar e dar corpo e língua a intensidades, fluidificações, poiésis ${ }^{3}$ e reproduções inerentes às polifonias geradoras de territórios singulares.

Esse modo de cartografar tem também inspiração no princípio antropofágico da deglutição do outro, sobretudo o admirado, de forma que partículas do universo desse outro se misturem às que já povoam a subjetividade do antropófago produzindo transmutação. Nesse sentido, é importante destacar que, para se realizar uma cartografia com pitadas de antropofagia, os procedimentos são sempre inventados de acordo com o contexto em que o cartógrafo se inventa, pois não se segue nenhuma espécie de protocolo normalizado. Busca-se abrir as condições para que o desejo possa ganhar expressão e atuar como entidade no jogo, pois entendido ali como vetor ativo no processo de produção de subjetividades. Concepção de desejo que não se liga à representação, à lei, à carência, à reatividade; ele é processo de produção, remete à vontade de criar, ao devir, pois são as necessidades que derivam do desejo e não o contrário (Deleuze e Guattari, 2004).

Dizemos, então, que o dizer-cidade é conjunto heterogêneo e trama tensa e polêmica, campo (político) de disputas discursivas pelo que "é" cidade em determinado momento, o que, por si, evidencia a relevância do refletir criticamente sobre as bases, as estratégias e os modos de agenciamento desse campo, interpelando-o de um lugar outro, que não é mais do que o mesmo lugar rasurado ${ }^{4}$ por um agenciar opaco. ${ }^{5}$ Dizê-lo campo de 
disputas é, para nós, relevante, pois permite fazer emergir concepções de cidade que irão substanciar desde grandes ações estatais (planos, políticas, normatizações, ações policiais, etc.) até as mais aparentemente desimportantes práticas cotidianas.

Instituindo esse campo da maneira delineada e desviando de qualquer intuito de juízo sobre o que seria, aí, a formulação correta, justa ou científica, interessa-nos problematizar a própria linguagem como modo de pensamento que permite a construção dos diversos tipos de discursos cidade. Não com a pretensão de que inventaríamos uma outra linguagem, um outro campo e, portanto, outros, agora sim "verdadeiros", dizeres-cidade. Mas com a perspectiva de nos apropriarmos dos dizeres predominantes rasurando-os e expondo esse rasurar, através de narrativasexperiência coletivas construídas como jogo (caosgrafias) com escrituras ditas dizendo cidade. ${ }^{6}$ Experiências que se instituem enquanto poiéticos dizeres-cidade no ensejo de traspassar seu tradicional traço empirista ou transcendental. ${ }^{7}$

0 caráter de jogo, predicado como modo às narrativasexperiência, expressa nossa aposta processual à possibilidade de explicitação de nossa interferência enquanto agentes provocadores ou narrantesjogadores, ao mesmo tempo que essa interferência fica posta à prova pela imprevisibilidade e pelo caráter errático do jogo. Tal jogo se configura, então, como um adentrar com "passo" próprio - operando em desvio uma discursividade cidade constituída como movimento interdiscursivo de dizeres-cidade, sendo interpelado por ele e interpelando-o.

Propomos, então, essas narráticas experiências cidade não como processos analíticos, etimológicos, semiológicos ou hermenêuticos, nem como crítica (em sentido geral, ou mesmo nos termos kantiano ou marxiano), nem, ain$\mathrm{da}$, como meios para alguma coisa (uma fala, um gesto, um escrito, uma fotografia), mas como o que denominamos "acontecimentos desconstrução". ${ }^{8} 0$ atributo "desconstrução" sinaliza, ao modo de Derrida (1975), o intuito de que o experienciar/acontecer se realize problematizando o dizer ontológico, logocêntrico, em termos tanto de derrubamento - de estruturas, absolutos, totalidades, origens, destinos, relações causa-efeito, funcionalidades -, quanto, no mesmo movimento, de transgressão poiética.

\section{e trajetórias e percursos e caosgrafias e}

A trajetória que chega às práticas caosgráficas é traçada com linhas tortas, intermitentemente de fuga e de territorialização, num zigue-zague rasurante, sobre um dito percurso de pesquisas no qual a problematização da linguagem e a dos discursos presentes no campo do planejamento urbano e regional e, de maneira mais ampla, da produção de cidades e territórios sedimentavam-se como elementos centrais. 0 jogo de linguagem, que é indissociavelmente produtor e produto dos processos de produção de cidade, mobilizava-nos a perguntar: quais agentes, sujeitos, instituições, tomam parte desse processo e quais os efeitos gerados por modos e formas como cada dizer cidade particular e determinado conjunto agenciado - em aliança ou em disputa conflitiva - é produzido. Mas também, em sinal invertido: tais dizeres não produzem também 
seus próprios enunciadores, contextos, interlocutores e objetos?

Nos percursos trilhados lá pelos idos de um incerto 2013, as caosgrafias se produziam diretamente em tensão aos dizeres-cidade que se afirmam absolutos, postulando-se como discurso verdadeiro, e tentam solapar a possibilidade de uma política. Naquele, então, 2013, referíamo-nos, sobretudo, àqueles que fundamentam e são explicitados pelo denominado "Planejamento Estratégico", discurso que vem sendo assumido por diversas administrações municipais, principalmente a partir da década de 1990, cujos postulados básicos concebem a cidade como algo a ser gerenciado em moldes empresariais, apontando para a necessidade de definir sua "vocação" e seu "diferencial". Subjaz a isso um pressuposto que despolitiza as dinâmicas de planejamento e gestão urbana, em nome da construção de consensos e de um projeto de cidade cuja meta é torná-la mais atrativa para empresas, investidores, mão de obra qualificada e turistas. Como hegemonia que se faz, desqualifica vozes ou discursos dissonantes ao seu dizer-cidade. Não os reconhece enquanto dizeres outros que podem disputar qualquer possibilidade de dizer-cidade porque não há, nesse dizer, a disputa mesma. Diante desse problema, o viés motivador das caosgrafias, afectando-se por um certo modo combativo de multidões que narramexperienciam rua, territorializa-se no dizer que essa disputa existe.

Nesse sentido, deixa rastros nas caosgrafias uma cidade do Rio de Janeiro dita como arena de disputas discursivas diretamente articuladas aos processos recentes - autoritários/ espetaculares - de transformação do território urbano. Utilizamos "dita" e não "descrita", pois constitui questão central das caosgrafias pensar (a/ uma/ um projeto de) cidade enquanto produção discursiva, posição que problematiza a ideia de que os discursos sejam "sobre a cidade", ou seja, representações de uma cidade "real" que já está aí e restaria dela falar. $\mathrm{A}$ cidade seria, nessa perspectiva, produção continuada a partir do que dela se fala (recorrendo a diferentes formas de linguagem), em que uma disputa política eminentemente discursiva emerge do encontro conflituoso de diferentes modos de dizer, de ver, de pensar, de instituir seus processos cotidianos. Evidentemente não se trata de movimento de mão única, pois os supostos sujeitos do discurso não estariam separados de um suposto objeto cidade, mas da construção de agenciamentos complexos, situados num espaço-tempo atual do qual participam fluxos transescalares, de geografias das mais locais às mais globais.

Esses agenciamentos vão constituindo "resultados parciais", rastros de rastros nos termos propostos por Derrida (2004), a partir de eventos cotidianos, de práticas ordinárias, de políticas públicas, de investimentos e especulações privados, de interações sociais no espaço público, de transformação das arquiteturas e dos espaços abertos, que compõem - individualmente e em suas relações - escrituras, sobre as quais novas escrituras se produzem: escrituras-cidade, ou dizeres-cidade. Esse processo, é preciso ressaltar, será sempre entrecruzado pelas tramas de dizeres que organizam o social, onde os diferentes sujeitos que colocam, ou não, uma disputa certamente não fazem em posição de igualdade. 


\section{fragmento caosgráfico $1^{9}$}

O choque de ordem agora era para valer . Era preciso ordenar as praias. Nada de fabricar, assar ou cozinhar alimentos. Camarão no espeto, o queijo coalho e o milho cozido ou assado não pode. Assim disse o chefe. Pra isso, vai botar fiscais para fazer valer a lei. Ainda bem que tenho um amigo que conhece lá o Grandão, o chefe dos fiscais. Ele me disse que, se eu não pisar na bola, consegue uma promoção. Vou ficar bonito! o que faço agora seu moço com os 100 guarda sóis e 200 cadeiras? olha só lá vem vindo meu freguês com os 2 poodles e 1 golden retriever. como são lindos correndo na praia e tomando banho de mar! proibido? que nada. meu freguês é chapa branca. Não entendi quando o chefe falou pra não mexer com o dono dos cachorros. Não é proibido? Ele disse que o homem é gente graúda. nessa vida seu moço já vi de tudo. hoje pode um pouco amanhã vai poder mais ainda e e ai? rsrsrsrs amigo moro aqui faz tempo. pois é não quero amolar com essa história. mas ouve só um pouquinho necessidade de desabafar. uns percebem logo logo as proximidades encostadas das oportunidades. foi isso. tempo morando aqui e disseram que tudo ia mudar que eu precisava ser consciente do progresso. O progresso exige que os obstáculos sejam transpostos (disse o chefe). Aquela gente era obstáculo. Interdiçom, preciso que você ajude! Seu serviço é fundamental para a continuidade do nosso trabalho. Temos um projeto a seguir: metas, tempo a ser cumprido. Essa gente atrapalha. foi assim. não sei se é verdade. a história tem seus vieses. a conversa poderia ter sido engenhosamente plantada por ele. não sei. só sei que saí. uns poderiam dizer que nicles foi saído. mas tinha o progresso. acho que é aquele da bandeira desde os inícios da escola. não é moço? fico triste não. interdiçom me convenceu. o pais precisa de mim o futuro o povo mais feliz rabiola colorida pipa bem no alto céu azul maravilha de cidade.

[-.].] Comentário: Ela quando chega é uma tortura pra valer não dá pra comparar Da choque de ordem leva tudo só não leva essa vontade que eu tenho de amar.
(Choque de Ordem, Grupo Nosso Grito)

\section{e caos e escritura e disputas e}

\author{
A trama discursiva e heterogênea que compõe \\ o campo de disputas entre dizeres-cidade pode
} ser vislumbrada à luz de um tipo de agenciamento proposto por Deleuze e Guattari (1996a) como produção a $n-1$, onde $n$ diz respeito à multiplicidade heterogênea e 1 diz respeito ao uno totalizante. No que viemos expondo até este ponto, o uno seria o discurso que se pretende instaurar consensualmente como único e verdadeiro, em meio à multiplicidade de discursos-outros, heterogêneos entre si e ditos minoritários em relação ao uno. Essa proposição provoca a necessidade contínua da operação de conjurar o uno, ainda que sem a possibilidade de escapar dele, a favor do múltiplo, da diferença e do heterogêneo, não apenas no âmbito das lutas contra os poderes constituídos - exoconsistência do dizer -, mas também no âmbito circunscrito à produção de resistências e contra-hegemonias - endoconsistência do dizer. Dizer cidade a n-1 como modo de expressar nesse dizer a inescapável tensão multiplicidade/unicidade.

Nas bordas, interstícios e zonas de sombra do dizer-cidade hegemônico, é produzida uma miríade de discursos outros que, ocupando a hegemonia com outros componentes (subjetivos, materiais, semióticos, afetivos), dizem resistir, desviar, produzir linhas de fuga ou simplesmente garantir existência. Minorias criadoras, diria Deleuze, que não se distinguem da maioria pelo número, mas por não se conformarem ao modelo, e sim serem tomadas por um devir, um processo. 


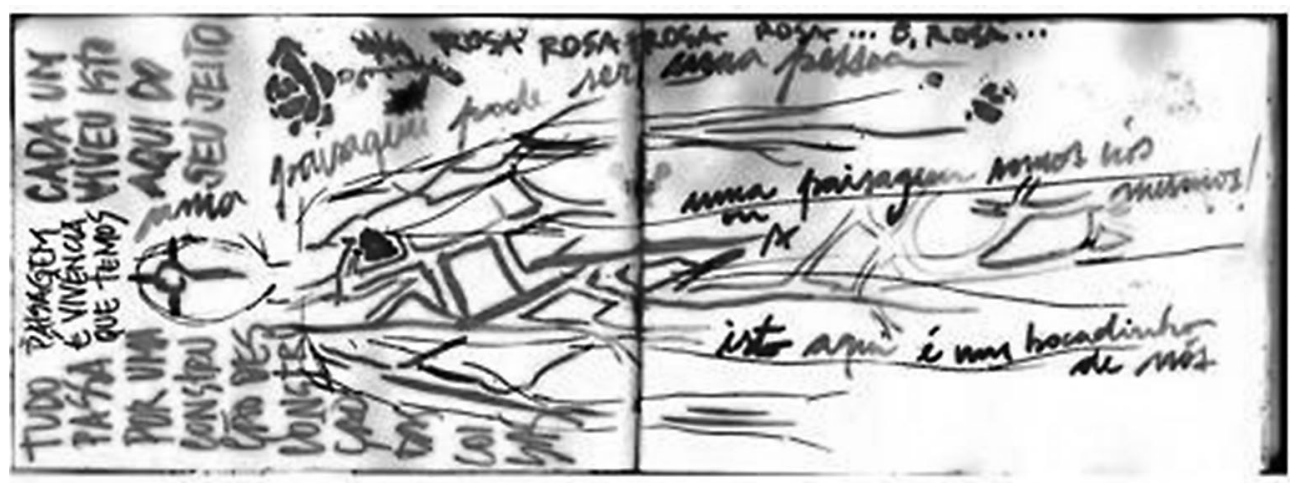

Fonte: Elaboração própria, 2014.

Quando uma minoria cria para si modelos, é porque quer tornar-se majoritária, e sem dúvida isso é inevitável para sua sobrevivência ou salvação (por exemplo, ter um Estado, ser reconhecido, impor seus direitos). Mas sua potência provém do que ela soube criar, e que passará mais ou menos para o modelo, sem dele depender. 0 povo é sempre uma minoria criadora, e que permanece tal, mesmo quando conquista uma maioria: as duas coisas podem coexistir porque não são vividas no mesmo plano. (Deleuze, 1992, p. 214)

Importa, assim, construir dizeres arrastados por devires de resistência, mas igualmente tomar cuidado contra a sedução em envelopar esses dizeres-cidade descontínuos e minoritários sob uma aura de pureza que os manteria imunes à feitiçaria capitalista (Pignarre e Stengers, 2011). A produção de subjetividade urbana ocorre em meio a fluxos em disputa, instaurando-se em processos de atualização incessante. Nesse movimento, uns e outros, agentes em agenciamentos, são atravessados por novos acontecimentos que produzem paradoxos e exigem um contínuo redizer(-se). Diante disso, faz-se necessário desconfiar de nossos dizeres e ter precaução no âmbito da produção discursiva, ou seja, problematizar a própria linguagem enquanto campo de conflitos a ser permanentemente tensionado. 


\section{Ilustração 2 - Disputas}

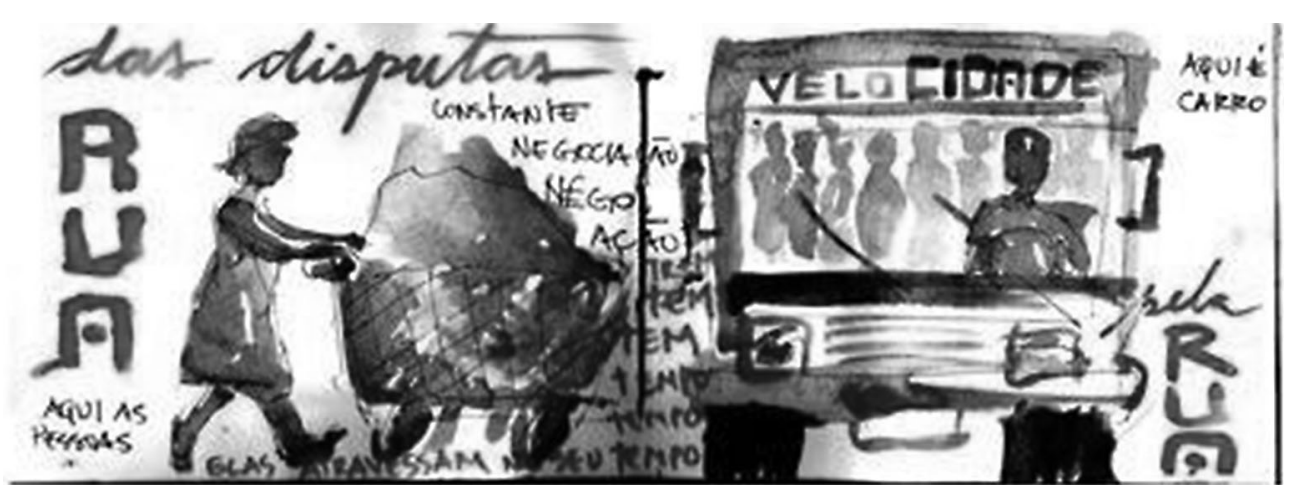

Fonte: Elaboração própria, 2014.

\section{fragmento caosgráfico 2}

"Manifestações ou sete atos e um desatino" Ato Gordo Elias ${ }^{10}$

[assim também]

palavras haviam feito seu trabalho, sulcando como imprecisos arados o que outras palavras dizem ser minha mente revolta. os rastros que aí deixaram, trazem ao lume cidades e impérios grandiosos, mas também esquinas escuras, postes tortos e enferrujados, ruínas de pequenas casas tristes, prédios que se dizem inteligentes, luzes insuportáveis, sorrisos sem rosto, euforias carnavalescas, peixes mortos a olhar o vazio, um pão mordido no chão de uma calçada imunda, perguntas sem resposta, esquecimentos de coisas que não se sabe, terrenos baldios em meio a milharais de prédios, avessos, meninas feinhas, milharais de espigas douradas, uma pequena chave que não sabe sua fechadura. esqueço, seleciono, rememoro, teço tramas, violento que me agencio. ajo: pego do chão o pão mordido e o devoro com prazer. penso: até o momento tenho conseguido não matar; com um pouco de sorte, seguirei evitando. falo: cidade.

[com efeito]

\section{e modo operativo-reflexivo e jogo e}

Como modo a essa aventura poiética, consideramos a condição da não suposição prévia e necessária do caráter dicotômico entre distinções clássicas do pensar hegemônico moderno, como aparência / essência, totalidade / parte, etc. Todo o trabalho tem como referências uma postura desconstrucionista derridiana, uma política dos afectos inspirada em conceitos como potência, devir e rizoma, de Deleuze e Guattari, e o método de montagem de Walter Benjamin. Essas referências não são objeto de apresentações apriorísticas, mas acionadas e discutidas na medida de necessidades surgidas durante 0 processo prático. 
A construção, enquanto agenciamento coletivo de enunciação (Deleuze e Guattari, 1996a; Guattari e Rolnik, 2005), de dizeres-cidade, sem formato ou modalidade de expressão predefinidos, tem por fundamento a tensão / interpelação entre fragmentos tempo-espaciais originários de agenciamentos díspares do cotidiano tomados a partir de determinado(s) dispositivo(s), fragmentos por vezes funcionais, por vezes desúteis (isto é, que colocam em xeque o primado da utilidade), e totalizações hegemônicas, em geral auto-assumidas eficazes pelo poder instituído.

Um dos pontos-chave do jogo é o momento no qual os fragmentos (sejam imagens, objetos, escritos, gestos, etc.) são produzidos pelos jogadores para compor arranjos e montagens sobre um tabuleiro que só passa a existir, que só se dá a ver, na própria dinâmica das composições, desvios, provocações e interpelações de cada jogada. Esse jogo, denominado "cartografia de afectos", opera na perspectiva da construção de dizeres que afirmam cidade enquanto enunciado(s) a $n-1$, tramados rizomaticamente. Isto é, um jogo que se propõe espaço de narrativaexperiência coletiva com a palavra cidade sem desta procurar decantar, sejam os modos mais completos ou complexos de se dizer / tomar / entender cidade - aquilo que faria una, idêntica a si mesma, realidade que preexiste aos discursos, às práticas que a dizem -, mas, antes, narrativaexperiência que toma a palavra, ela mesma, como território de disputa, matéria plástica que se faz e refaz incansavelmente nos jogos discursivos, nas indissociáveis micro e macropolíticas cotidianas. (a-)regras do jogo

Se jogos se efetuam pela definição prévia de regras, nas caosgrafias sua própria formulação, revisão, descarte e reelaboração constituem questão central ao que consideramos uma investigação teoricoprática de criação coletiva de narrativasexperiência voltadas ao pensar cidade, política, linguagem. Dizemos, então, de cada caosgrafia como narrativaexperiência singular, mas também podemos dizer de momentos que, por potência de fazer jogar, ganharam condensação e territorialidade no jogo e também um nome, que possivelmente já diz algo. Indicados a seguir em sequência, num propositado acidente pedagógico, podem, entretanto, trocar de posição, se misturar ou mesmo sumir em cada jogo, com exceção do último - despacho - que só acontece quando há necessidade e desejo produzidos no jogo para desdobrar o agenciamento coletivo de enunciação ali elaborado em expressões que podem ser partilhadas além dos limites espaço-temporais do jogo (um evento, uma publicação, um ato público, etc.).

Enrosco: onde são definidos coletivamente dispositivos provocadores de uma deriva que pode, contudo, ocorrer tanto em espaços considerados abertos como também fechados (afinal onde começa e termina cidade?). São utilizados exercícios livremente adaptados do teatro e da dança para mobilizar o corpo inteiro ou os corpos-corpo coletivo, a potencializar-se enquanto máquinas expressivas que maquinam(-se) (n)o jogo caosgráfico. 


\section{Imagem 1 - Momento Enrosco em oficina} com estudantes de arquitetura na UFF

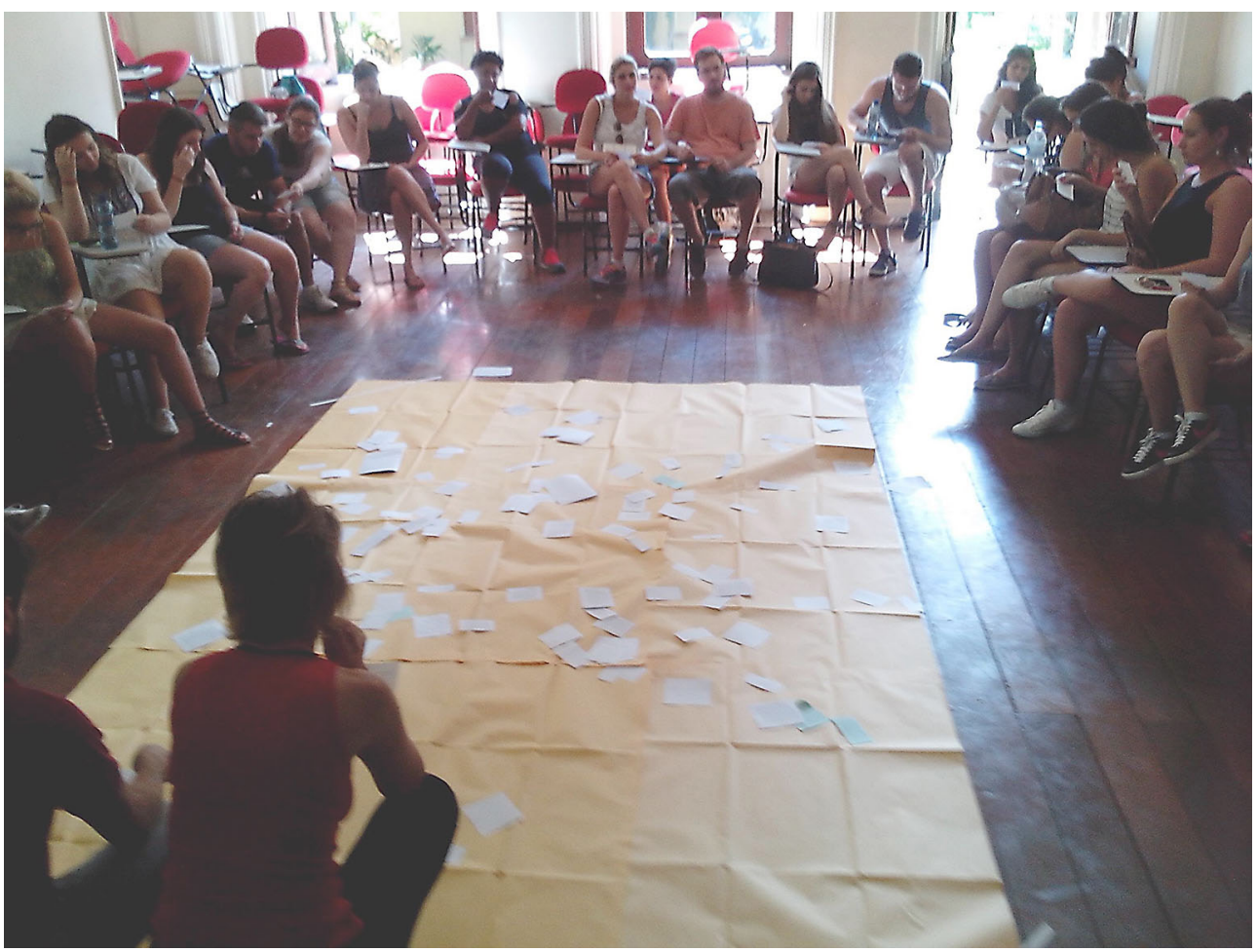


Imagens 2 e 3 - Momento Enrosco com estudantes grevistas na UFRJ
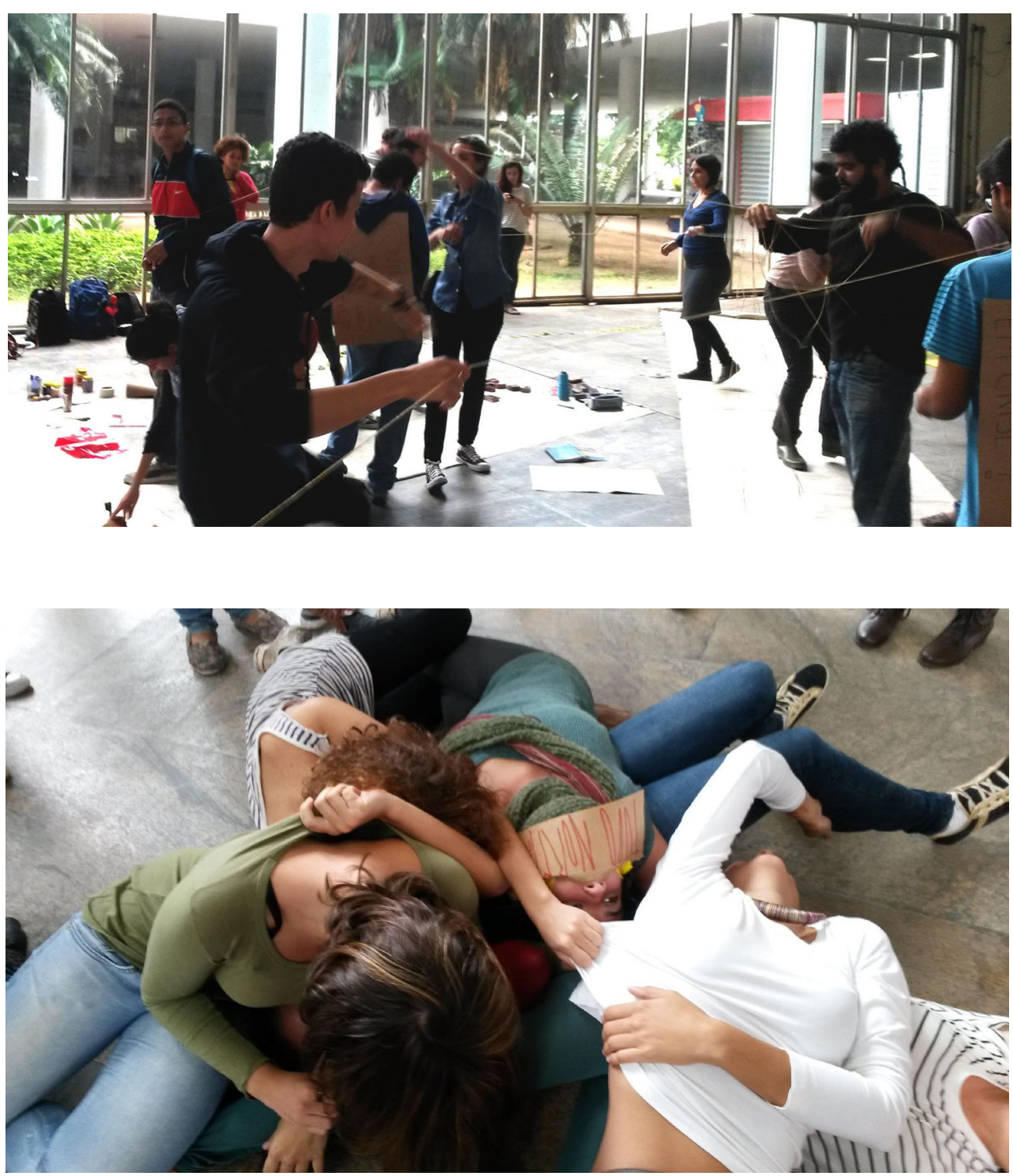
Deriva / produção de fragmentos: onde Deriva é provocada como movência e delírio e composição de corpos e coisas em deslocamento (pela cidade, pelo espaço, pelos dispositivos, pelos sentidos, pelas sensações, pelos sujeitos e pelas ideias ligadas a essas palavras), visando a ativar o sensível mobilizado pelo dispositivo disparador do jogo, a fim de produzir (coletar, compor, criar) fragmentos. No âmbito do jogo, fragmentos são qualquer tipo de matéria de expressão - encontros e garimpos, emergências, devires e atravessamentos significativos e apropriados pelos participantes para constituir a matéria bruta a ser agenciada numa cartografia de afectos. Podem ter diversos formatos: imagens, textos, fotografias, falas, gestos, objetos, vídeos, sons, gente, bicho, planta, etc.

Imagens 4 a 7 - Exemplos de Fragmentos e Derivas

e dispositivos de produção de fragmentos
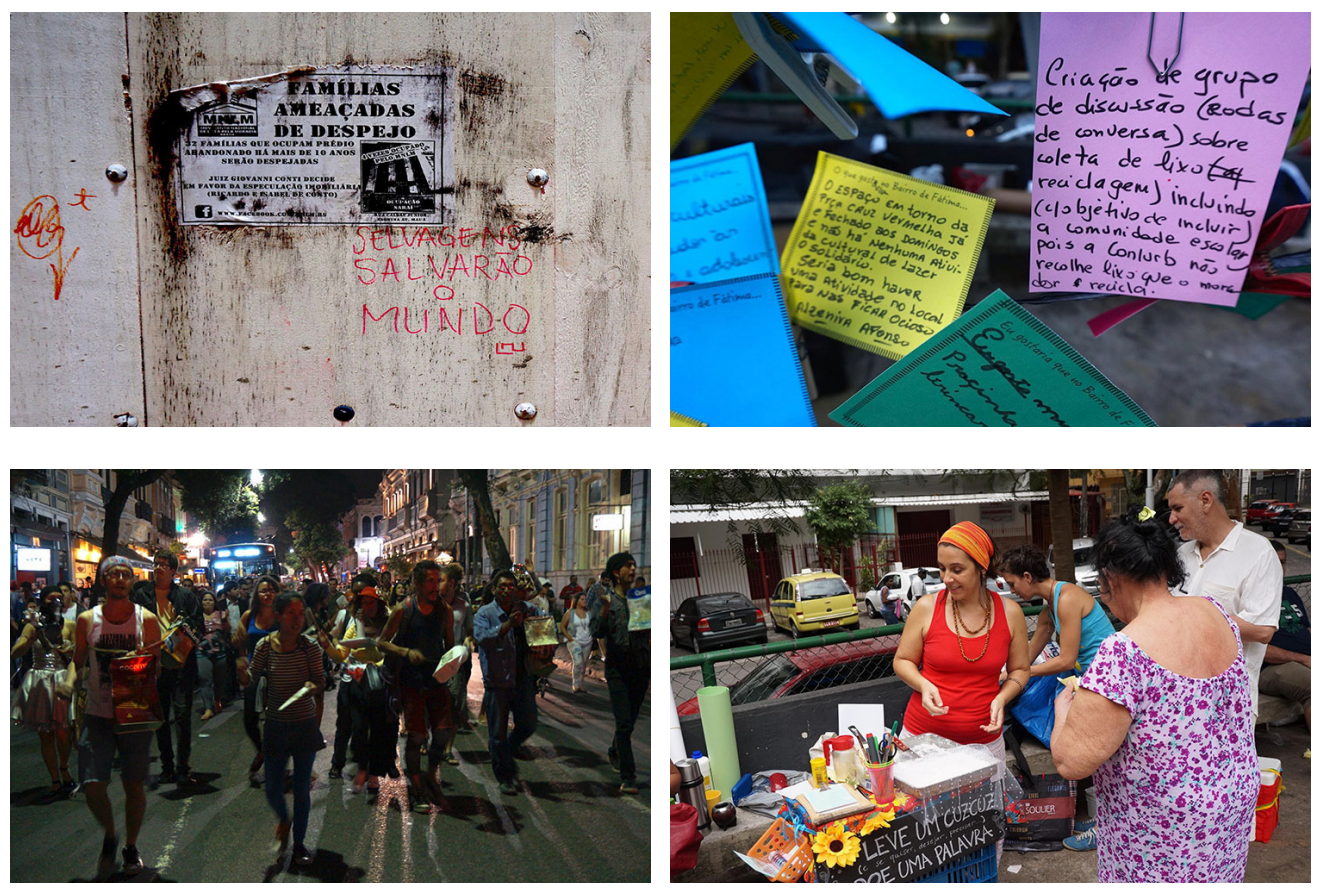
Tabuleiro: onde os fragmentos produzidos são apropriados e atualizados livremente como peças para constituir jogadas elaboradas por um ou vários jogadores, de modo sucessivo ou simultâneo, a depender da própria dinâmica que se instaura em cada jogo. Um plano de composição se produz, no qual as jogadas podem se espacializar e temporizar, constituindo o que chamamos de uma cartografia de afectos, em que cada jogada é provocada por afectações de outras jogadas, e dizeres cidade fragmentários passam a compor também outro dizer cidade múltiplo, um agenciamento coletivo de enunciação, a partir de conjunções, conexões, disjunções, proximidades, distâncias, intensidades, marcas, colisões, rasuras e sobreposições entre jogadas.

Imagem 8 - Momento Tabuleiro em oficina com participantes do XIX Congresso Iberoamericano de Geografia, Universidade do Minho, Portugal

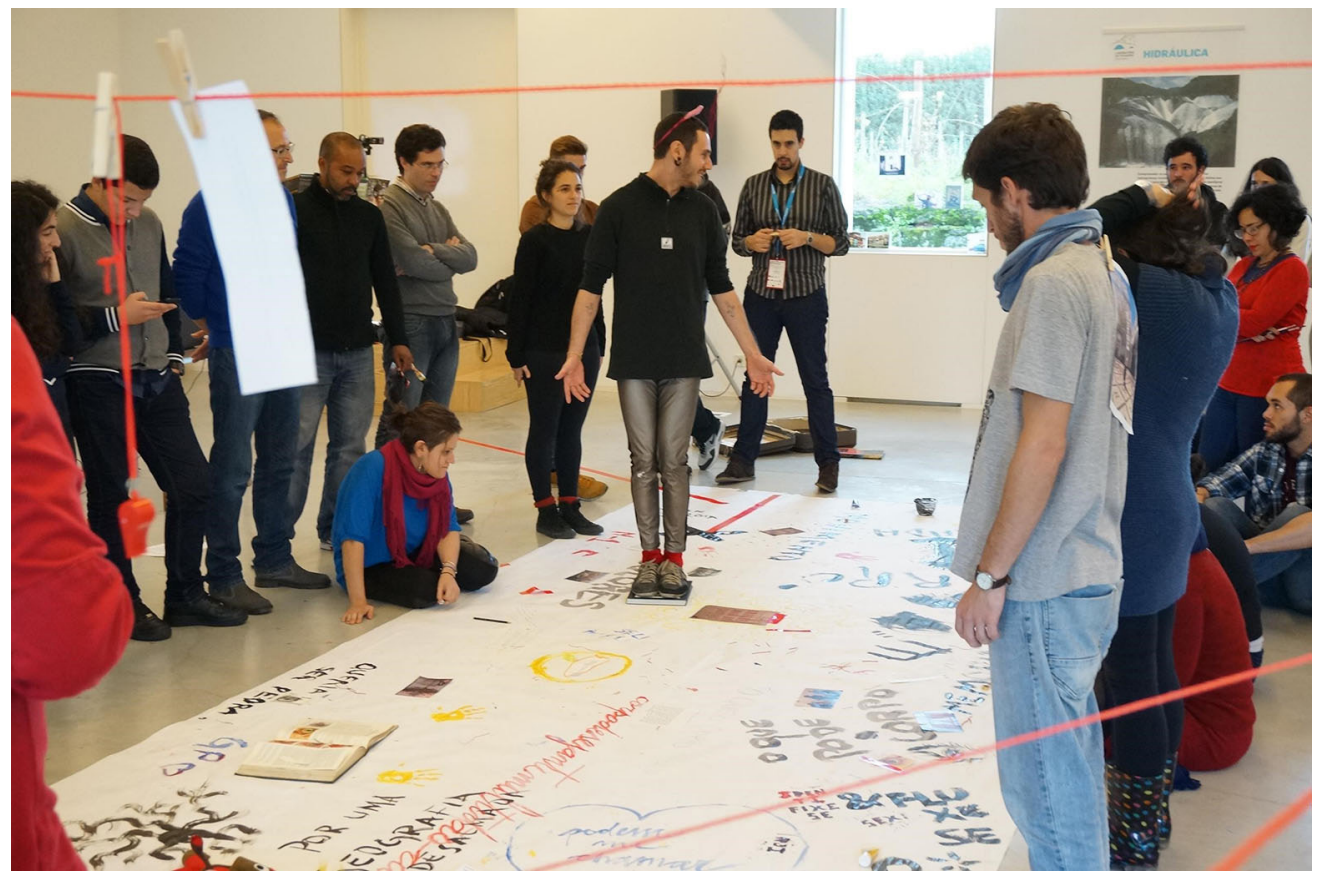


Despacho: quando o jogo, pela potência de afectações, não se deixa terminar e os participantes elaboram estratégias e/ou táticas a fim de estendê-lo além das próprias fronteiras de seu acontecimento. São, então, produzidos desdobramentos da cartografia de afectos em linguagens múltiplas, com recursos e suportes disponíveis encontrados e passíveis de serem operarados pelos jogadores. Já foram feitos despachos em meios diversos, como audiovisual, material gráfico, textos publicados, apresentações em eventos, instalação de estruturas não permanentes e performances em espaço público.

Imagens 9 a 11 - Despachos executados em meios diversos. Na ordem em que aparecem: trecho de um material gráfico; intervenção em uma praça pública de Porto Alegre; instalação na UFRJ
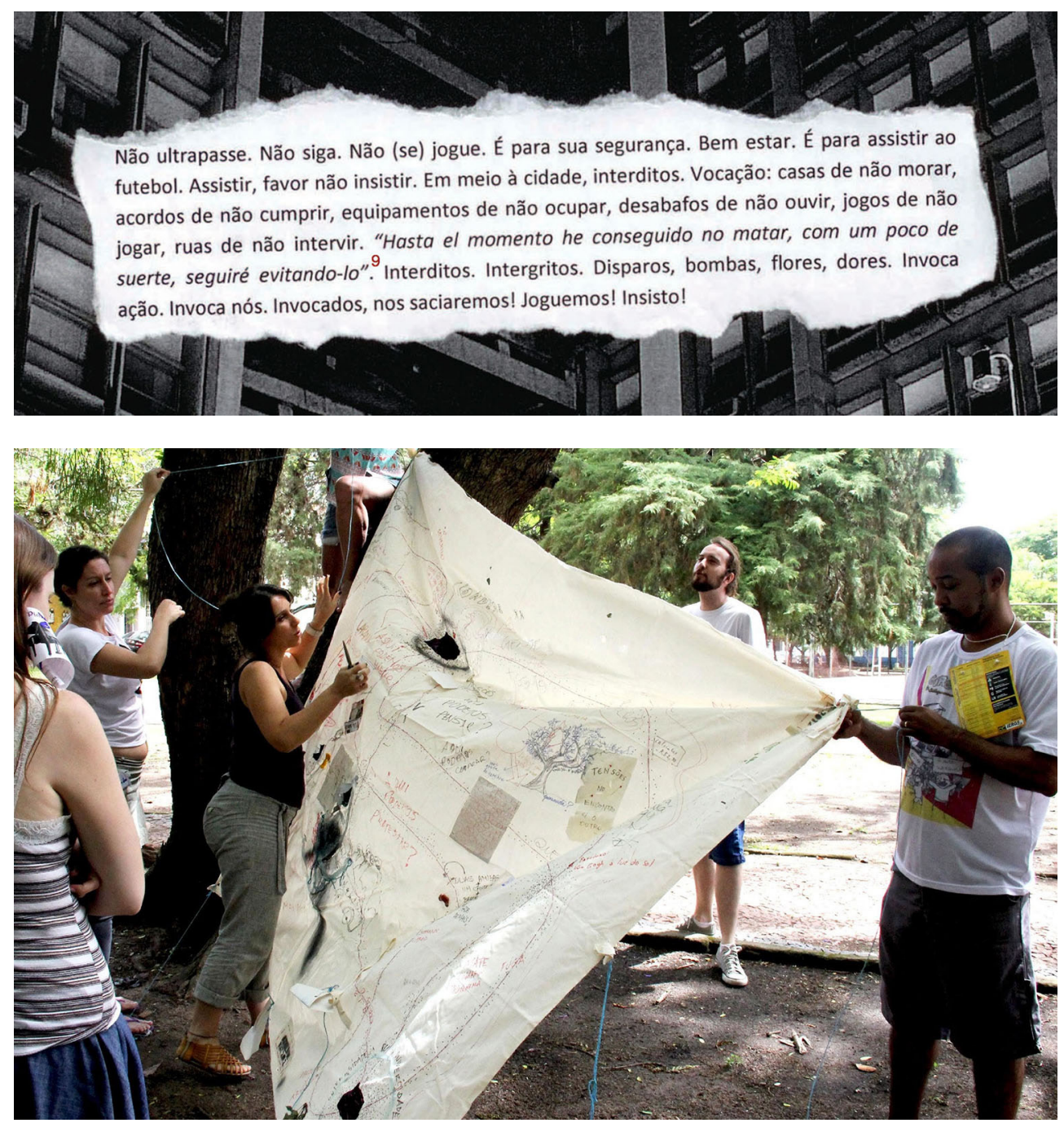


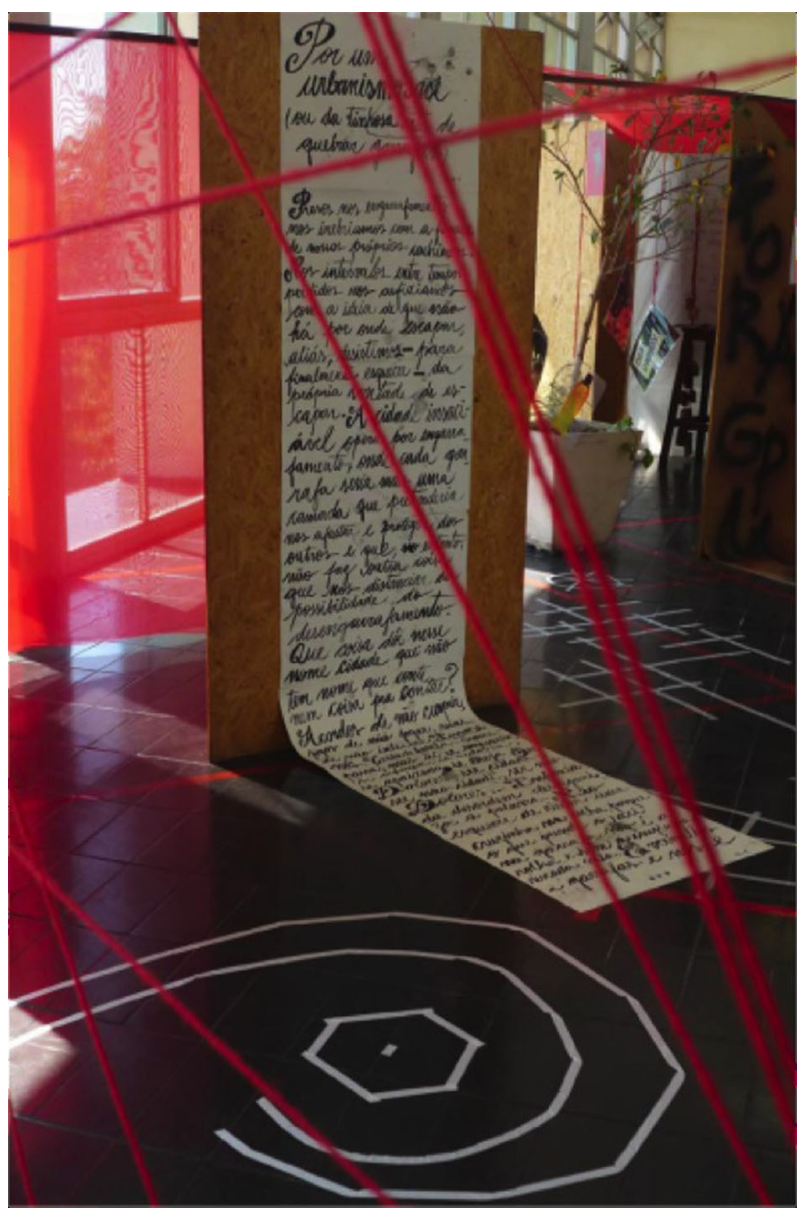




\section{fragmento caosgráfico 3}

Estado-jogo ${ }^{11}$

Esse movente caos palavrório, não obstante, tem a potência de individuar por afectação, não aquela supostamente determinada por alguma essência imaginada, mas a afectação possibilitada pelos planos de intensidades que fazem o jogo. Essa individuação - como aqui assumida, uma ecceidade rasurada, se tivermos em conta os termos em que Deleuze e Guattari (1997a) a formulam. ${ }^{12}$ No acontecimento constituído pelo presente indefinido da escrita, instituo e me afecto por outro acontecimento, aquele de um fluxo de ecceidades - que designo como sons e formas e durações e odores e texturas e volumes e cores e temperaturas e distâncias - a se mover aceleradamente, desenhando e desfazendo figuras doces ou ameaçadoras e outras nem tanto.

Interpelado e definitivamente arrebatado por essa afectação, jogador desejante que me faço, desdobro-a em jogo movente de outras ecceidades [...] cujas intensidades se agenciam por e como errância e reverberação e frequência e insistência e contração e curto-circuito e amplificação e multiplicidade e aceleração e adensamento e agregação e simultaneidade e intercalação e acréscimo e eliminação e violência e difusibilidade e superposição e, a constituir "plano de consistência", é agenciamento, redobra explodida em multiplicidade de palavras, elas também redobras de redobras, ecceidades de ecceidades de outras palavras na infinitude do jogo enquanto potência de negação do mesmo.

\section{breve apontamento}

\section{experenciaragenciarnarrar}

Caosgrafias são também concebidas na trama imbricada dos termos experenciar-agenciar-narrar, na qual a experiência não é considerada fora do processo narrativo. Experiência e narrativa se instituem, assim, na própria relação, como agenciamento coletivo de enunciação. Experienciar como agenciarnarrar.

\section{fragmento caosgráfico $4^{13}$}

- "Isaura experiencia". Tomar essa escritura ao modo diabólico enunciado, no intuito de dizer um sentido a ela, por efêmero que possa ser o que possa ser dito, enquanto também um (outro) experienciar, quer dizer considerar que o nome Isaura não indica um sujeito experienciador (uma presença), nem que o verbo experienciar significa previamente qualquer coisa, especialmente o confrontar sensorial / racional / subjetivo de uma suposta presença com alguma alteridade, também presença em si e por si. Quer dizer, como rasura a esse experienciar como relação de presenças, que a escritura "Isaura experiencia", entendida como narrativa a (n-1), não dizendo então de coisas ou estados de coisas autônomas e independentes a esse dizer, ainda que assustada por esses fantasmas e por vezes incorporando-os conciliadoramente, sugere um agenciar múltiplo de palavras que constitui como trama de intensidades ao mesmo tempo um si mesmo, outros 
desse si, os modos de tecedura ou jogo entre eles (a-regras do jogo) e o devir desse jogo.

- Narraragenciarexperienciar Isaura é como narraragenciarexperienciar deserto, ou como desertar ou deserdar. Abandono. Solidão de abismo. Nenhuma referência pra frente ou pra trás, ainda que se siga ao mesmo tempo pra frente e pra trás, nenhum norte identificável a priori, nenhum dia, nenhuma noite a pontuar de saída os dizeres. Dizeres escrituras, agenciamentos comerfalarcomerfalar.

- Experienciar como territorializar. Nem sempre, mas algumas vezes capitais. Territorializar como experienciar, como um incorporal acontecer experienciaragenciarnarrar.

\section{relato 1 ... narrativasexperiência caosgráficas}

Pode-se dizer que o que chamamos caosgrafias se constitui tanto ou mais no campo das práticas e das técnicas que dos conceitos e mesmo da metodologia. 0 mais profundo é a pele. No entanto, a primeira narrativaexperiência caosgráfica (que só pode existir como tal no presente incerto desta escrita) distingue-se das demais por ter sido concebida a partir do propósito de dar conta da montagem de um filme, cuja principal pretensão era a completa horizontalidade na sua produção. Uma criação coletiva e horizontal, ao menos quanto às "regras" do jogo, foi o que motivou o desenvolvimento de caosgrafias. Assim, o processo tinha um caráter mais instrumental. Até então, pode-se dizer que as pessoas implicadas buscavam uma ferramenta capaz de garantir a abertura e a simetria na criação e na montagem do filme. Hoje, as virtudes de uma mirada retrospectiva possibilitam que muitas delas concordem que esta foi a versão mais "dura" das caosgrafias. Apesar de muitos fatores estarem relacionados a essa questão, o principal deles é que, naquele momento, estávamos caosgrafando para atingir um objetivo.

Porém, não precisou muito para que tivéssemos a sensação que o modo caosgráfico era muito mais potente do que sua capacidade de gerar um produto. Ainda assim (porque é complicado descer das árvores para as raízes), pensamos que o que tínhamos criado era realmente uma "metodologia", capaz de ajudar a fazer um filme com tais características. ${ }^{14}$ Já naquela narrativaexperiência havia surgido 0 incômodo do contraste no momento em que passávamos da etapa denominada "cartografia de afetos" para a montagem dos fragmentos em uma timeline, que comumente enseja certa linearidade no tempo.

Esse incômodo vinha da sensação de que submeter a caosgrafia à função de organizar uma montagem em linha era por demais dissonante com a abertura provocada pelo processo. Não pela montagem do filme em si mesmo, mas porque este nos parecia acabar sempre, mesmo com todas as advertências, tomando o caráter de resultado, de produto e mesmo de objetivo, ao qual todo o processo anterior parecia subordinado.

Tal desconforto se tornou mais intenso em outra ocasião, na qual o método tomou 0 formato de oficina e, assim, evidenciava fissuras que deslocariam o núcleo do trabalho para o processo, muito mais do que para sua finalização. Ainda assim mantivemos a produção de um filme como etapa final do processo. ${ }^{15}$

Foram dois dias povoados de encontros intensos. Pessoas de diferentes partes do País, 
de diferentes formações, idades e vontades se inscreveram na oficina. Uma conversa inicial marcou as primeiras impressões sobre 0 que se desenrolaria nos momentos posteriores. A etapa que propusemos em seguida foi de nos dividirmos em grupos para recolher "fragmentos" (os elementos a serem agenciados na experiência da "cartografia de afetos") da cidade de Salvador. As etapas seguintes se constituíram por distintas formas de realização de tarefas, que cada "grupo" passou a considerar como um caminho para aquilo que pretendia constituir.

Inicialmente o modelo de funcionamento era o mesmo que o da primeira caosgrafia. Compusemos cartas que se referiam às cenas que constituímos a partir de uma seleção prévia das imagens trazidas pelos grupos. Assim, era como se as "cartas" pudessem fazer referência a algo dado. Completo equívoco. Que se tornou evidente quando os participantes começaram a fazer jogadas com seus próprios corpos, rompendo primeiro com a "bidimensionalidade" das conexões que propúnhamos e especialmente com uma referencialidade ingênua, que acabamos por reproduzir internamente no processo. Ao jogar seus corpos sobre o nosso "tabuleiro", as pessoas caosgrafaram a cartografia, o jogo e, logicamente, toda a oficina.

Permitimo-nos, naquele então, pensar que não são as regras ou as formulações $a$ priori que definem o processo, ainda que participem dele. Caosgrafar é uma prática, que se instaura como modo de experenciarnarrar coletivo. Distanciando-se de certas motivações iniciais, o principal para nós tornou-se "provocar pensamento", no sentido proposto por Isabelle Stengers em relação à noção de cosmopolítica, quando a filósofa se pergunta e lança sua provocação:

Como apresentar uma proposição que não pretende dizer o que é, ou o que deveria ser, mas que provoque pensamento; e que não exige outra verificação além de ser capaz de desacelerar o raciocínio e criar a ocasião para a emergência de uma sensibilidade ligeiramente diferente relativa aos problemas e situações que nos mobilizam? ${ }^{16}$ (Stengers, 2007, p. 45)

Não faz sentido, portanto, ter a expectativa de que estamos diante de um novo modelo de fazer política ou planejamento, não porque a caosgrafia exclua qualquer política ou planejamento de si mesma, assim como não exclui um modelo, mas porque nela tudo é jogo de corpolinguagem. Não tem por objetivo nem explicar e menos ainda solucionar os problemas que se apresentam no cotidiano da cidade. 0 que está em jogo nesta proposta de experiência é a criação de práticas que tenham como consequência a abertura do campo de enunciações, ou seja, das possibilidades de dizer-cidade.

\section{relato 2 ... narrativasexperiência caosgráficas}

Desde as primeiras caosgrafias até as mais recentes, pode se dizer que partiram de um certo roteiro, que continha em si determinada expectativa. Almejava-se um produto: um texto acadêmico, uma apresentação em congresso, um filme ou vídeo. Então, passou-se à ocupação do espaço, o interior de um edifício moderno, a feitura de uma instalação, uma praça pública, e demo-nos conta de que bastava estarmos 
reunidos em modo-jogo para dizer da situação como caosgráfica. A caosgrafia deixava de ser dita como metodologia para desenvolver produtos e passava a ser dita como processo movente, podendo acontecer nas mais diversas formatações e contextos e instaurar-se entre nós (porque um entre e um nós são pré-requisitos fundamentais) sem planejamento, de surpresa. 0 modo-jogo não precisava ser acionado, mas ele acionava-nos a jogar a partir de algo que se instaurava entre nós.

Aos poucos, começamos a ver caosgrafia em muitas situações, algumas bem comuns. Músicos improvisando uma música juntos sem terem ensaiado, uma jogada perfeita em uma pelada de futebol, a coreografia astuciosamente funcional, ainda que lenta, de uma sarjeta ocupada em movimento ao mesmo tempo por gente, carros, motos, bicicletas, carroceiros, lixos, buracos, poças d'água e exus. E por que não capoeira angola, o jogo de olhares do flerte, embriagar-se e pular carnaval? Há algo comum a essas narrativasexperiência da ordem de uma desracionalização ou desatenção; não completas, mas rasuradas pelos circuitos de afectos que cruzam a narrativaexperiência de espaço-tempo. Seria errado, por isso, dizer de uma troca do racional pelo afetivo, pois as duas formas podem ser ao mesmo tempo percepções e afectações e costumam mesmo ocorrer simultaneamente. Além disso, talvez se possa dizer que é preciso prestar mais atenção aos afectos e levá-los a sério, ao passo que pode ser libertador não conferir um protagonismo permanente ao racional. Não achamos que inventamos algo novo ou descobrimos algo que não existia, mesmo porque não nos parece possível dar conta de alguma totalidade que seja essência ou aparência de que tentamos falar. Apenas escolhemos um nome para dizer algo que acontece. Esse nome, entretanto, mobiliza-nos, gera desentendimentos entre nós, convoca-nos a jogar e estimula um contínuo redizer de certezas e exploração dos limites da linguagem. Por isso tudo, e por muito menos, as caosgrafias são atualmente plurais no plural.

\author{
Entrando por uma porta, \\ saindo por outra, \\ quem quiser que vá \\ narrandoagenciandoexperienciando \\ outra. ${ }^{17}$
}

\section{Frederico de Araujo}

Universidade Federal do Rio de Janeiro, Instituto de Pesquisa e Planejamento Urbano e Regional, Grupo de Pesquisa Modernidade e Cultura. Rio de Janeiro, RJ/Brasil.

fredaraujo@uol.com.br 


\section{Notas}

$\left({ }^{*}\right)$ Texto elaborado pelo Grupo de Pesquisa Modernidade e Cultura do Instituto de Pesquisa e Planejamento Urbano e Regional, da Universidade Federal do Rio de Janeiro, coordenado por Frederico Guilherme Bandeira de Araujo, com agenciamento de Amanda Rosetti da Silveira, Ana Cabral Rodrigues, Flávia de Sousa Araújo, Frederico Guilherme Bandeira de Araujo, Gabriel Schvarsberg, Heitor Levy Ferreira Praça, laci D’Assunção Santos, Laura Souza Rêdes, Letícia Castilhos Coelho, Natalia Velloso Santos, Priscila Medeiros de Oliveira, Raphael Soifer, Ricardo José de Moura, Ronieri Gomes da Silva Aguiar e Samuel Thomas Jaenisch.

(1) Fragmento-epígrafe, autoria própria.

(2) Caos enquanto lugar da criação de todas as formas e que desconhece, também, os diferentes níveis de enfrentamentos que com ele mantêm as três formas de pensar e criar: filosofia, ciência e arte (Magnavita, 2012, p. 210).

(3) O termo poiésis está aqui relacionado aos conceitos de heterogênese ou multiplicidade, no sentido das construções conceituais de Deleuze e Guattari (2004), os quais afirmam que a realização de uma poiética (ou poética - originária da palavra grega poiésis) significa fabricar, criar, confeccionar.

(4) Rasura assumida aqui em termos derridianos, como borrar fronteiras, tachar palavras, abalar estruturas, desdobrar e riscar essências, reescrever naturezas, devir sem fim, instaurar errâncias, esvanecer origens, tornar destinos brumosos, arguir verdades, multiplicar interpelações, desviar de rota, fazer espaço do tempo, fazer tempo do espaço, etc. "A rasura instaura uma economia vocabular. $O$ entre-aspas, o tipo gráfico da impressão, as letras riscadas e as expressões irônicas devem ser entendidas como manifestações da estratégia desconstrutora em Derrida. Usando termos de uma linguagem que quer desconstruir, Derrida abala essa linguagem e inscreve um sentido outro além dela [...]. Sendo a rasura uma modalidade de solicitação e estratégia, funciona como elemento regulador da polissemia e estabelece uma lógica de suplementaridade na própria sintaxe em que se inscreve" (Santiago, 1976, p. 71).

(5) O termo "opaco", neste projeto, usado no sentido usual na literatura teórica sobre cinema, de desnudar o caráter fílmico do filme, em oposição ao termo "transparente" que, ao inverso, corresponderia ao sentido de ocultamento desse fato. Com essa perspectiva, então, a expressão "agenciar opaco" indica um modo reflexivo/expositivo marcado pela preocupação em explicitar que se trata de um processo operado a partir de específicas questões, estratégias e procedimentos.

(6) "Escritura", em perspectiva derridiana, enquanto jogo (Derrida, 2008), como modo, e enquanto marca (notação e conteúdo respectivamente diferidos) como forma, de qualquer tipo ou natureza: orto-gráfica, imagética, geo-gráfica, arquitetural, urbanística, gestual, comportamental, sonora.

(7) Só é possível usar aqui essa noção sob rasura, na medida em que pertence à história da metafísica. Como afirma Derrida, “'Experiência' sempre designou a relação a uma presença, tenha ou não esta relação a forma da consciência. Devemos, todavia, de acordo com essa espécie de contorção e de contenção à qual o discurso é aqui obrigado a esgotar os recursos do conceito de experiência antes e com o fim de alcançá-la, por desconstrução, em sua última profundeza" (2004, p. 74). 
(8) "Acontecimento" considerado em primeira inspiração ao modo da noção deleuzeana homônima (cf. Deleuze, 1974), todavia, efetivamente operado aqui através de rasura dessa noção. Diz Deleuze: "Inseparavelmente o sentido é o exprimível ou o expresso da proposição e o atributo do estado de coisas [...] É, exatamente, a fronteira entre as proposições e as coisas [...]. É nesse sentido que é um 'acontecimento': com a condição de não confundir o acontecimento com sua efetuação espaço-temporal em um estado de coisas. Não perguntaremos, pois, qual é o sentido de um acontecimento: o acontecimento é o próprio sentido. $O$ acontecimento pertence essencialmente à linguagem, ele mantém uma relação essencial com a linguagem; mas a linguagem é o que diz das coisas" (p. 23). A rasura que fazemos desse dizer inspirador corresponde ao entendimento de que o que pode ser dito como "proposição", "fronteira" e "estado de coisas" não excede, e não há como exceder, à própria linguagem. Assim assumindo, "acontecimento", diz de, uma ocorrência linguística plena, envolvendo ditos objetos, significantes, significados e sentidos.

(9) Trecho do trabalho "e remoinhos e cidades de leva e traz y Dolores e" (GPMC, 2013).

(10) Trecho do trabalho “Manifestações ou sete atos e um desatino" (GPMC, 2014a), autoria própria.

(11) Trecho do trabalho "Manifestações ou sete atos e um desatino" (2013), autoria própria.

(12) “Uma ecceidade não tem nem começo nem fim, nem origem nem destinação; está sempre no meio. Não é feita de pontos, mas apenas de linhas. Ela é rizoma” (Deleuze e Guatarri, 1997, p. 50).

(13) Trechos do trabalho "Rastros do sem-nome que o diga" (GPMC, 2014b), autoria própria.

(14) O filme "Perlenga Cangaço" foi realizado com apoio do Ministério da Cultura - Secretaria do Audiovisual - Edital de concurso n. 1, de 29 de janeiro de 2010: Concurso de Apoio à Produção de Obras Cinematográficas Inéditas, de curta metragem, de fiç̧ão ou documentário.

(15) O trabalho coletivo realizado pelos participantes da referida oficina foi o filme "Talvez Salvador" (2011).

(16) Livre tradução a partir do original: "Comment présenter une proposition dont l'enjeu n'est pas de dire ce qui est, pas non plus de dire ce qui doit être, mais de faire penser, et qui ne demande pas d'autre vérification que cela: la manière dont elle aura "ralenti» les raisonnements, créé l'occasion d'une sensibilité un peu différente par rapport aux problèmes et aux situations qui nous mobilisent?".

(17) Trechos do trabalho "Rastros do sem-nome que o diga" (GPMC, 2014b), autoria própria.

\section{Referências}

BUTANG, A. (1996). Abecedário Gilles Deleuze - L'Abécédaire de Gilles Deleuze Avec Claire Parnet. [Documentário/Entrevista]. Direção de André Butang. França. Duração 8h aprox.

DELEUZE, G. (1974). Lógica do sentido. São Paulo, Perspectiva. (1992). Conversações. São Paulo, Editora 34. 
DELEUZE, G. (2007). Francis Bacon: lógica da sensação. Rio de Janeiro, Jorge Zahar.

DELEUZE, G. e GUATTARI, F. (1996a). Mil Platôs - capitalismo e esquizofrenia, v. 1. Rio de Janeiro, Editora 34.

(1996b). Mil Platôs - capitalismo e esquizofrenia, v. 3. Rio de Janeiro. Editora 34.

(1997a). Mil Platôs - capitalismo e esquizofrenia, v. 4. Rio de Janeiro, Editora 34.

(1997b). Mil Platôs - capitalismo e esquizofrenia, v. 5. Rio de Janeiro, Editora 34.

(2004). O Anti-Édipo - Capitalismo e esquizofrenia I. Rio de Janeiro, Imago/Lisboa, Assírio e Alvim.

DERRIDA, J. (1975). “Posições. Diálogo com Jean-Louis Houdebine e Guy Scarpetta”. In: Discurso Social. Posições. Semiologia e Materialismo. Lisboa, Plátano.

(2004). Gramatologia. São Paulo, Perspectiva.

(2008). “La Différance”. In: Márgenes de la Filosofia. Madrid, Catedra.

GPMC - Grupo de Pesquisa Modernidade e Cultura (2012). Talvez Salvador: rastros de uma oficina feita de imagem, som e movimento. Revista Redobra, v. 10, pp. 78-85.

(2013). Off Sinas Cidade: e remoinhos e cidades de leva e traz y Dolores. In: XIX SEMANA DE PLANEJAMENTO URBANO E REGIONAL. Anais. Rio de Janeiro, Ippur/UFRJ.

(2014a). Manifestações ou sete atos e um desatino. In: XX SEMANA DE PLANEJAMENTO URBANO E REGIONAL. Anais. Rio de Janeiro, Ippur/UFRJ.

(2014b). Rastros do sem-nome que o diga. In: XX SEMANA DE PLANEJAMENTO URBANO E REGIONAL. Anais. Rio de Janeiro, Ippur/UFRJ.

GUATTARI, F. e ROLNIK, S. (2005). Micropolítica: Cartografias do Desejo. Petrópolis, Vozes.

MAGNAVITA, P. R. (2012). Experiência Rizomática. Revista Redobra. Salvador, n. 9, ano 3.

PIGNARRE, P. e STENGERS, I. (2011). Capitalist sorcery: breaking the spell. Londres, Palgrave Macmillan.

ROLNIK, S. (2006). Cartografia Sentimental: transformações contemporâneas do desejo. Porto Alegre, Sulina e Editora da UFRGS.

SANTIAGO, S. (org.) (1976). Glossário de Derrida. Rio de Janeiro, Francisco Alves.

STENGERS, I. (2007). “La Proposition Cosmopolitique”. In: LOLIVE, J. e SOUBEYRAN, O. (orgs.). L'Émergence des Cosmopolitiques. Paris, La Découverte.

Texto recebido em $5 / j u n / 2016$

Texto aprovado em 25/jul/2016 